\title{
KINETICS OF ISOPENTANE DEHYDROGENATION ON CHROMIA-ALUMINA CATALYST WITH CATALYST FOULING*
}

\author{
Hideo NODA, Setsuji TONE and Tsutao OTAKE \\ Department of Chemical Engineering, Faculty of Engineering Science, \\ Osaka University, Toyonaka
}

\begin{abstract}
In isopentane dehydrogenation over chromia-alumina catalyst, the conversion of isopentane and the yield of isopentenes decreased rapidly with process time while that of isoprene did so very slowly.

Coke deposition on catalyst and catalyst fouling occurred in an integral catalytic reactor, and coke distribution was observed along the axial direction of the reactor. For isopentane dehydrogenation a kinetic model in which the main reaction was consecutive and the sub-reaction was parallel is proposed. For estimating distributed kinetic parameters with catalyst fouling, an algorithm that involves two calculating steps is introduced. Applying an activity factor which accounts for catalyst fouling and which is a linear function of coke content, the kinetic parameters were estimated. Using these parameters, the changes of the concentration and the distribution of coke content with process time were simulated fairly well.
\end{abstract}

\section{Introduction}

In catalytic reactions, cracking ${ }^{20)}$, isomerization ${ }^{22)}$, hydrogenation ${ }^{19)}$, and so on, an activity distribution along the axial direction of the reactor usually occurs due to coke deposition on catalyst, and it varies with process time. Froment and Bischoff ${ }^{4)}$ treated the distribution of the catalyst activity theoretically in the reactor. Several studies $\left.^{9}, 14,17,19\right)$ dealing with reactions with fouling, discussed the catalyst activity as a function of an average coke content. Recently, to aid process design ${ }^{3,23,24)}$ and to obtain optimization ${ }^{15,18)}$, an expression of the catalyst activity as a function of process time was introduced. The derived optimal policies or kinetic model would include uncertainties of the deactivation model and discrepancy between the observed and the evaluated values because of simplification of the catalyst fouling and coke formation. It is necessary to represent the catalyst activity profile precisely, but there have been only a few studies that analyze complex reaction kinetics with catalyst fouling. Gavalas $e t$ al. ${ }^{7,8)}$ dealt with the problem of estimating catalyst activity profiles from current operating reactor data of naphtha reforming by a parametrization technique. Tone et al. ${ }^{20)}$ developed a kinetic model for the relation between methylcyclohexane cracking and coke formation, and showed that by the activity factor, which was expressed as a function of coke content, the

\footnotetext{
* Received on June 18, 1973

Presented at the 37th Annual Meeting of The Soc. of Chem. Engrs., Japan, at Nagoya, April, 1972

干560 豊中市待兼山町1-1

大阪大学基礎工学部化学工学科 野田秀夫
}

calculated values of both the product and coke content distribution in a fixed bed agreed fairly well with the observed values.

The purpose of this study was to develop a kinetic model for the dehydrogenation of isopentane that is useful for process design and optimization. The dehydrogenation of isopentane was studied in an integral packed reactor at various levels of temperature and contact time, and the distribution of coke content was measured. A kinetic model including coke formation was assumed. The kinetic parameters in the model are estimated by a new algorithm which is constructed by two calculating steps. Firstly, under an assumption that the rate constants are uniform through the reactor, average or lumped kinetic parameters were evaluated by the non-linear least square method. The function of activity factor was determined from the lumped rate constants, relating to the average coke content. Secondly, the activity factor with coke content could be used to represent the coke distribution in the catalytic bed, and as a result a simulation of the reaction kinetics was accomplished. From the best-fits between the experimental and calculated values, the proposed kinetic model was useful to simulate isopentane dehydrogenation with catalyst fouling.

\section{Experimental}

\section{1 Gatalyst}

The catalyst used was a commercial chromiaalumina pellet catalyst (N-402, Nikki Chemical Co.) of a size $5 \mathrm{~mm} \phi \times 4.5 \mathrm{~mm}$. The catalysts were crushed and sieved to three particle sizes-8-10 mesh, 16-32 mesh and 40-60 mesh, and were calcined in an air 
stream for at least 3 hours at $550^{\circ} \mathrm{C}$. Mainly the $16-32$ mesh catalyst was used.

\section{2 Apparatus and procedure for dehydroge- nation of isopentane}

To study the dehydrogenation of isopentane, a flow system was used as shown in Fig. 1, operating essentially at atmospheric pressure. The reactor, which was a $10 \mathrm{~mm}$ I.D. by $325 \mathrm{~mm}$ long quartz tube, contained catalysts fixed by quartz wool. The reactor was placed in a fluidized sand bath which was maintained at constant temperature by means of a P.I.D. controller. Two stainless sealed chromel-alumel thermocouples, $1 \mathrm{~mm}$ O.D., were positioned along the axis of the reactor to measure the temperatures within the catalyst bed; these were recorded continuously.

The hydrocarbons used were ultrapure grade isopentane, 2-methyl 2-butene (2M2B), 2-methyl 1butene $(2 \mathrm{M} 1 \mathrm{~B})$, or isoprene. As the boiling points of the materials were close to $30^{\circ} \mathrm{C}$, a syringe of a microfeeder was set in an ice bath to prevent the materials escaping in vapor. When the reactor reached a given temperature, nitrogen gas was exchanged with feed gas of definite composition of hydrocarbon diluted with nitrogen. A contact time $(\tau)$ was defined by $z / U_{v}$ on the space velocity at $300{ }^{\circ} \mathrm{C}$, ranging from 0.06 to 3.6 sec. The products were analyzed on line by gas chromatography; the total effluent from the reactor passed through the heated $\left(\right.$ at $50^{\circ} \mathrm{C}$ ) gas sampler (HGS-2 Shimadzu). Isopentane, isopentenes (2M1B, $2 \mathrm{M} 2 \mathrm{~B}$ and $3 \mathrm{M} 1 \mathrm{~B})$ and isoprene were separated in a column containing $15 \% \beta$ - $\beta^{\prime}$-oxydipropionitrile on $\alpha$ alumina. The experimental conditions are shown in Table 1. Three sizes of catalysts and the pellet were tested to determine the resistance of intraparticle diffusion on conversion at a reaction temperature of $536^{\circ} \mathrm{C}$. For catalyst particle less than 16-32 mesh, resistance of intraparticle diffusion was negligible, and the 16-32 mesh catalyst was used for measurement of reaction rates for all runs.

\section{3 Measurement of coke content}

After a reaction run was over, the catalyst bed was divided into equal sections about $1.5 \mathrm{~cm}$ long (about $1.0 \mathrm{~g}$ ) along the reactor. The coke-deposited catalyst of the section was drawn out by vacuum line one after another. An average coke content of the $m$-th section from the inlet of the reactor was $\bar{n}_{c m}$. A coke content, $n_{c m}$ as shown in Figs. 2-4, was given as an arithmetic mean of $\bar{n}_{c m-1}$ and $\bar{n}_{c m}$.

The weight of the coke on the catalyst was determined in a thermogravimetric balance by burning off coke with air. Furthermore, to measure the ratio of carbon to hydrogen in coke, experiments of coke combustion were carried out by the same apparatus as shown in Fig. 1. About $3 \mathrm{~g}$ of coke catalyst was placed into the reactor. After desorption of the adsorbed water by nitrogen at $250^{\circ} \mathrm{C}, 200 \mathrm{cc} / \mathrm{min}$ of dried air was passed through the reactor at about $620^{\circ} \mathrm{G}$. $\mathrm{CO}$ and $\mathrm{CO}_{2}$ were separated in a column containing silica gel-activated carbon with helium carrier gas while

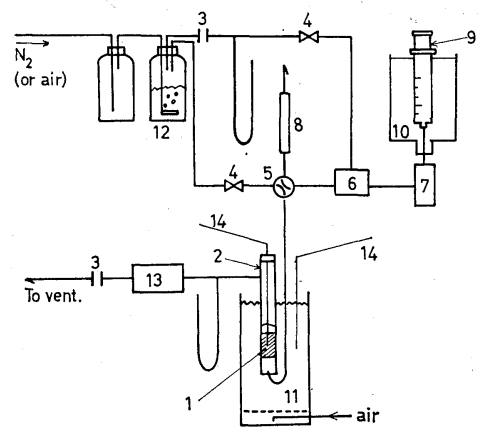

1 catalyst

2 quartz reactor

3 gas flow meter

4 needle value

5 four way valve

6 mixer

7 vaporizer

8 condenser

9 microfeeder

10 cooler

11 fluidized bed

12 drier

13 heated gas sampler

14 thermocouple

Fig. 1 Flow diagram of experimental apparatus

\section{Table 1 Experimental conditions}

Concentration of hydrocarbon 0.143

(Isopentane, Isopentenes,

[mole fraction]

Isoprene) diluted with

nitrogen

Flow rate of nitrogen

200

[cc. $\mathrm{STP} / \mathrm{min}$ ]

(Dilution gas)

1) Differential Reactor

Catalyst weight (wcat)

Catalyst size

Reaction temperature Contact time $(\tau)$

2) Integral Reactor

Catalyst weight (wcat)

Catalyst size

Reaction temperature

Contact time $(\tau)$
$0.1-1.0$

16-32

536

$0.06-0.6$

1.0-12

16-32, 8-10, 40-60

$5 \mathrm{~mm} \phi \times 4.5 \mathrm{~mm}$ pellet

488-560

$0.6-3.6$ $[\mathrm{g}]$

[mesh]

$\left[{ }^{\circ} \mathrm{C}\right]$

[sec]

[sec] polyethylene glycol $20 \mathrm{M}$ with hydrogen carrier gas was used to separate $\mathrm{H}_{2} \mathrm{O}$. The average composition of the coke was found to be from approximately $\mathrm{C}_{1} \mathrm{H}_{0.15}$ to $\mathrm{C}_{1} \mathrm{H}_{0.05}$.

\section{Experimental Results}

To examine the reaction models, three kinds of hydrocarbons, i.e. isopentane, 2M2B and isoprene, were used under differential reactor conditions. In the feed of isopentane, coke formation was negligible, but in the feed of 2M2B or isoprene considerable coke deposited on the catalyst. With an integral reactor (contact time $0.6 \mathrm{sec}$, at $536^{\circ} \mathrm{C}$ and for process time $70 \mathrm{~min}$ ), the average coke deposition from isopentane was about $40 \mathrm{mg}$-coke/g-cat., that from 2M2B was about $220 \mathrm{mg}$-coke/g-cat., and that from isoprene was $250 \mathrm{mg}$-coke/g-cat. In the dehydrogenation of isopentane in an integral reactor, a rapid rise of temperature to $60^{\circ} \mathrm{C}$ was observed in the catalyst bed during 1 to $3 \mathrm{~min}$ of process time. It was considered that there might be exothermic reactions at an initial process time-rapid coke formation, polymerization and so forth. At least five minutes was allowed for the system to reach steady state, so sample for reactant was taken ten minutes later.

Isopentanes were $2 \mathrm{M} 2 \mathrm{~B}, 2 \mathrm{M} 1 \mathrm{~B}$ and $3 \mathrm{M} 1 \mathrm{~B}$, and ratios of each component were not dependent on process time, but only on temperature. Isopentenes $(2 \mathrm{M} 1 \mathrm{~B}, 2 \mathrm{M} 2 \mathrm{~B}$ and $3 \mathrm{M} 1 \mathrm{~B})$ are in equilibrium with each other as reported by Ishii et al. ${ }^{11)}$. 


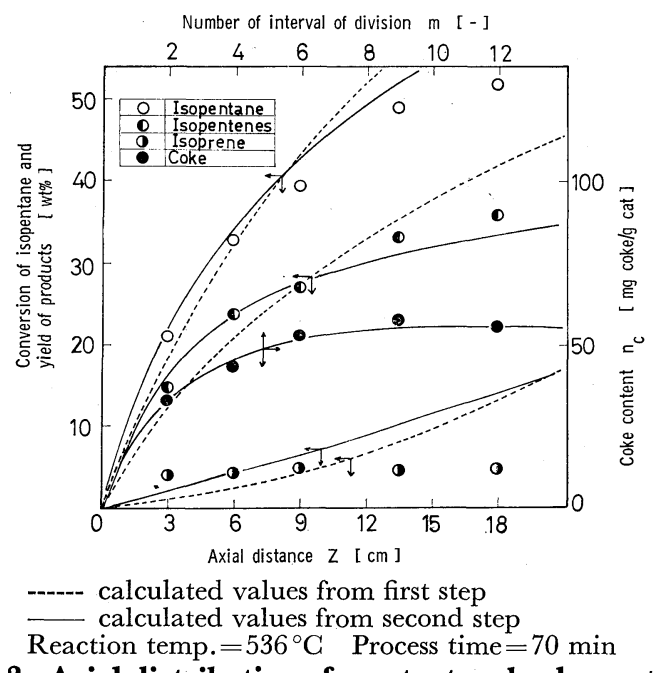

Fig. 2 Axial distribution of reactant and coke content

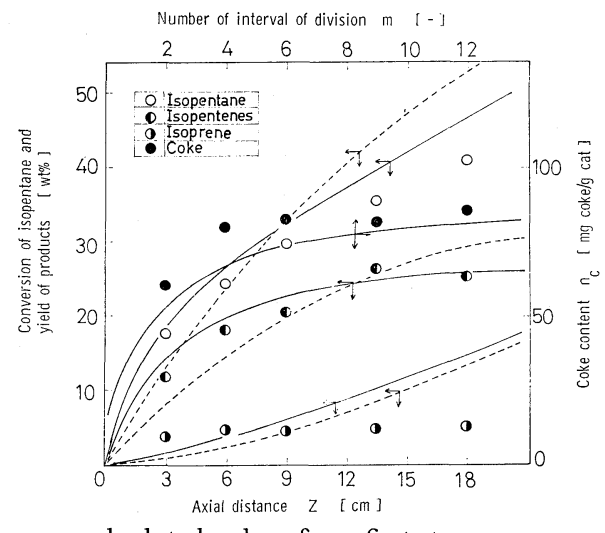

----- calculated values from first step

- calculated values from second step

Reaction temp. $=536^{\circ} \mathrm{C}$ Process time $=130 \mathrm{~min}$

Fig. 3 Axial distribution of reactant and coke content

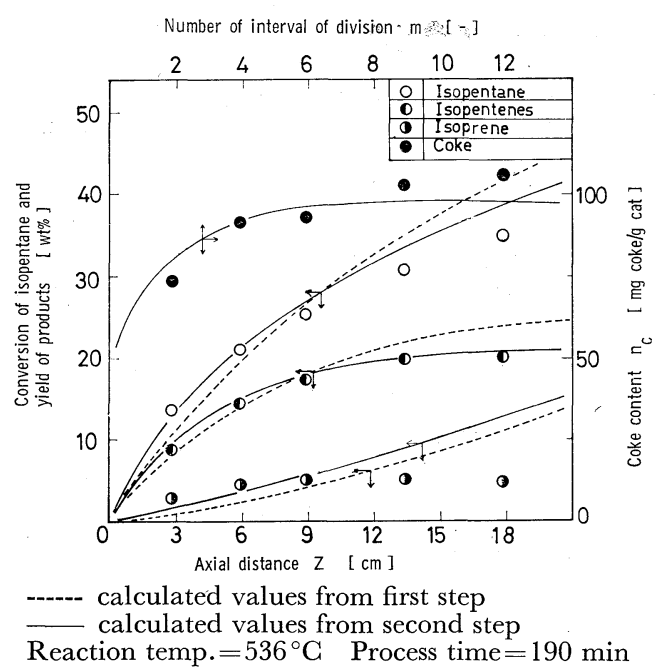

Fig. 4 Axial distribution of reactant and coke content

Figures 2-4 show the yields of products as a function of axial distance at three different process times. From these figures we see that the conversion of isopentane and the yield of isopentenes increases approximately exponentially with contact time, but that of isoprene is almost constant. Fig. 5 illustrates typical plots of the conversion and the yields of products against the process time at three different temperatures. The con-

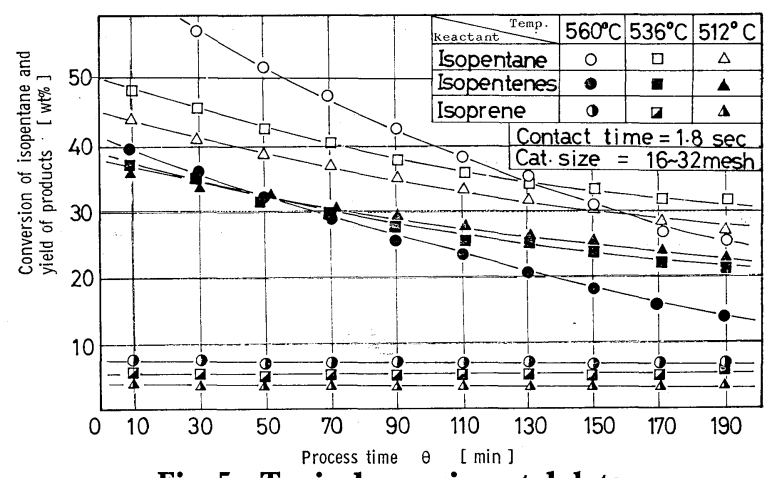

Fig. 5 Typical experimental data

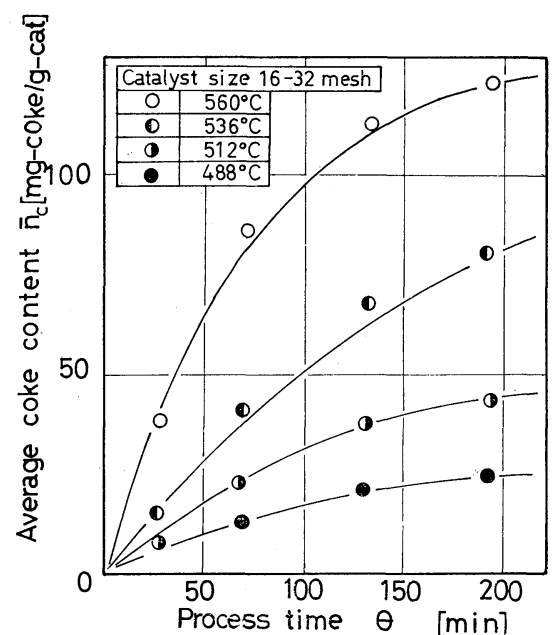

Fig. 6 Average coke content $\left(\bar{n}_{c}\right)$ vs. process time $(\theta)$ on experimental results

version of isopentane and the yield of isopentenes decreased rapidly while that of isoprene did so slowly.

The distribution of the coke content $n_{c m}$ is shown in Figs. 2-4. Plots of weight per cent of average coke all over the catalyst bed against process time are shown in Fig. 6.

The average coke is given by

$$
\bar{n}_{c}=\int_{0}^{L} n_{c} d z / L=m^{-1} \sum_{m=1}^{m} \bar{n}_{c m}
$$

Figures 5 and 6 indicate that the average coke content increases with both temperature and process time increases, while the conversion and the yields decrease.

\section{Analysis of Experimental Results}

\section{1 Kinetic model}

The dehydrogenation of isopentane was reported by Mavity et al. ${ }^{12)}$ as a consecutive reaction (isopentane $\rightarrow$ isopentenes $\rightarrow$ isoprene) under condition of various feed rates, pressure and so on. According to Ishii et $a l .10,11)$ it was noted that dehydrogenation from isopentane to isopentenes was a first-order reaction, and that $2 \mathrm{M} 1 \mathrm{~B}$ and $3 \mathrm{M} 1 \mathrm{~B}$ were the intermediates to isoprene.

The dehydrogenation was accompanied by coke formation during the process. Coke is not only formed via olefin as reported by Takeuchi et al. ${ }^{19)}$, Eberly et al. ${ }^{5)}$, Otake et al. ${ }^{10)}$, but also via diolefin, as obtained from 
the experimental results.

The reaction includes thermal cracking, isomerization, polymerization, etc. It is assumed that dehydrogenation of isopentane takes place in consecutive steps, that cracking occurs in parallel from isopentane, and that coke formation is via both isopentenes and isoprene. The kinetic scheme thus assumed is shown in Fig. 7.

1) The rate of isopentane disappearance is given as a first-order reaction;

$$
\begin{aligned}
& r_{A}=\left(k_{1}+k_{2}\right) C_{A} \\
& r_{A_{1}}=k_{1} C_{A} \text { (reaction rate for olefin) } \\
& r_{A_{2}}=k_{2} C_{A} \text { (reaction rate for other products) }
\end{aligned}
$$

2) That of the dehydrogenation to isopentenes is given as a first-order reaction;

$$
r_{B}=k_{1} C_{A}
$$

3) That of the dehydrogenation to isoprene is given as a $p$-th order reaction;

$$
r_{C}=k_{3} C_{B}^{p}
$$

4) That of the coke formation is given as a $p$-th order reaction from isopentenes and a $q$-th order reaction from isoprene;

$$
\begin{aligned}
& r_{n_{c}}=\nu\left(k_{4} C_{B}^{p}+k_{5} C_{C}^{q}\right) \\
& r_{n_{1}}=k_{4} C_{B}^{p} \text { (reaction rate from isopentenes) } \\
& r_{n_{c 2}}=k_{5} C_{C}^{q} \text { (reaction rate from isoprene) }
\end{aligned}
$$

By introducing an activity factor, $\phi_{i}$, the rate constants are defined as

$$
k_{i}=k_{0 i} \phi_{i}
$$

where $k_{0 i}=$ initial rate constant at $n_{c}=0$. In general, an activity factor is a function of process time and contact time.

\section{2 Simulation of reaction kinetics}

Using the assumptions that (a) the feed gas is a plug flow, (b) there are negligible gradients of temperature and pressure through the reactor, (c) axial diffusion is negligible, (d) intraparticle diffusion is negligible, and (e) there is no interparticle or intraparticle mass and heat transfer rate limitation, it is possible to describe four coupled continuity equations given below;

$$
\begin{aligned}
\frac{\partial C_{A}}{\partial \theta}+U_{v} \frac{\partial C_{A}}{\partial z} & =-r_{A} \\
\frac{\partial C_{B}}{\partial \theta}+U_{v} \frac{\partial C_{B}}{\partial z} & =r_{A_{1}}-r_{C}-r_{n_{C 1}} \\
\frac{\partial C_{C}}{\partial \theta}+U_{v} \frac{\partial C_{C}}{\partial z} & =r_{C}-r_{n_{C 2}} \\
\frac{\partial n_{C}}{\partial \theta} & =r_{n_{C}}
\end{aligned}
$$

As the integral reactor with coke formation is at unsteady state, and in general has an axial distribution of coke content, it is very difficult to determine the rate

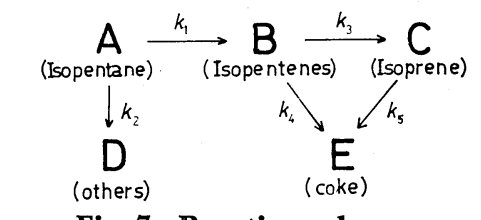

Fig. 7 Reaction scheme

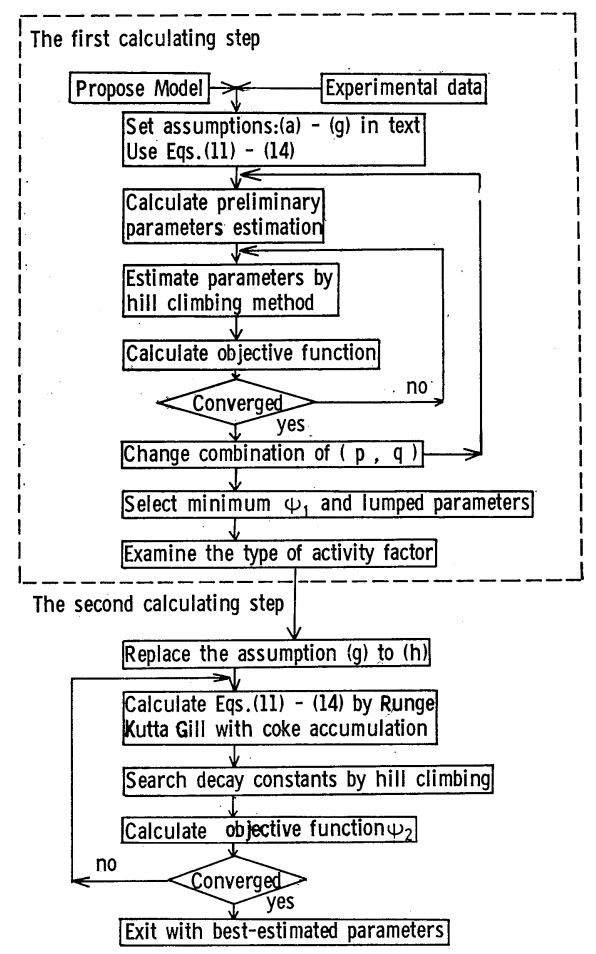

Fig. 8 Algorithm for estimation of a distributed parameter system

constants in distributed parameter system as described by Eqs.(7)-(10). In addition, we shall make an assumption that (f) contact time is much shorter than process time for catalyst decay, so that the quasi-steady state approximation is valid.

Under this assumption, Eqs.(7)-(10) are reduced to

$$
\begin{aligned}
& \frac{\partial C_{A}}{\partial \tau}=-\left(k_{1}+k_{2}\right) C_{A} \\
& \frac{\partial C_{B}}{\partial \tau}=k_{1} C_{A}-\left(k_{3}+k_{4}\right) C_{B}^{p} \\
& \frac{\partial C_{C}}{\partial \tau}=k_{3} C_{B}^{p}-k_{5} C_{C}^{q} \\
& \frac{\partial n_{C}}{\partial \theta}=\nu\left(k_{4} C_{B}^{p}+k_{5} C_{C}^{q}\right)
\end{aligned}
$$

But Eqs.(11)-(14) are still distributed parameter system, so an algorithm, which is constructed by two calculating steps, for kinetic parameter estimation as shown in Fig. 8 is introduced.

\subsubsection{The first calculating step}

On the assumption that (g) the catalyst activity is uniform through the bed, the experimental data of the $i$-th component, $\hat{G}_{i j k}$, were compared with the calculated values, $C_{i j k}$, at process time $\left(\theta_{k}\right)$ and at contact time $\left(\tau_{j}\right)$. That of coke content, $n_{c j}$, was plotted against process time and the rate of coke formation, 


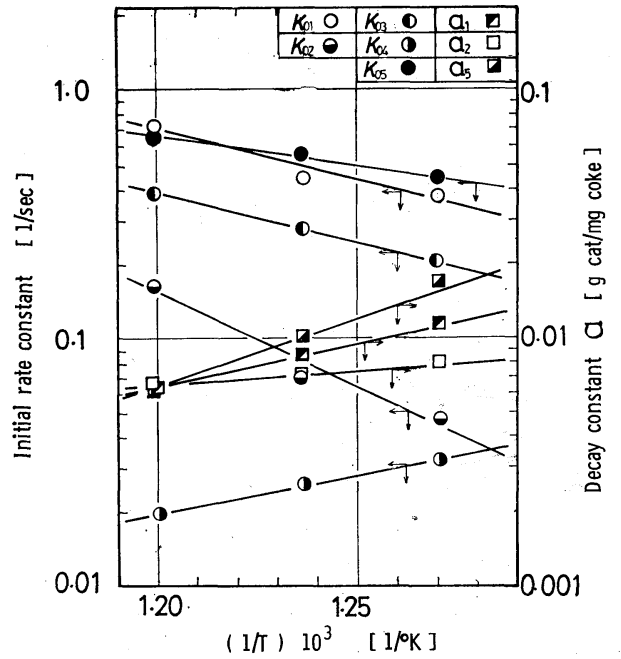

Fig. 9 Arrhenius plot

$r_{n_{c j}}$, was obtained by graphical differentiation.

The problem can be stated as one of finding $\bar{k}_{1}$ to $\bar{k}_{5}$ such that an objective function defined by Eq.(15) has a minimum value.

$$
\psi_{1}=\sum_{i} \sum_{j}\left\{\omega_{i}\left(\hat{C}_{i j k}-C_{i j k}\right)^{2}+\omega_{n_{c}}\left(\hat{r}_{n_{c j}}-r_{n_{c j}}\right)^{2}\right\}
$$

where $\omega_{i}$ is a weighting factor for the $i$-th component. The objective function was minimized by a hill climbing method with the NEAC-2200 digital computer (at Osaka Univ. calculation center). The values of reaction order, $p$ and $q$, were changed with four combinations of $(1,1),(1,2),(2,1)$ and $(2,2)$. As the result of calculations, the reaction orders $p$ and $q$ were found to be $(1,1)$. The lumped rate constants, $\bar{k}_{i}$, calculated from this step were related to average coke content, $\bar{n}_{c}$. From the linearity of the plots, the following relation was obtained.

$$
\bar{k}_{i}=k_{0 i} \phi_{i}\left(\bar{n}_{c}\right)
$$

and

$$
\phi_{i}\left(\bar{n}_{c}\right)=1-\bar{\alpha}_{i} \bar{n}_{c}
$$

where $\bar{\alpha}_{i}=$ lumped decay constant.

3.2.2 The second calculating step

The assumption $(\mathrm{g})$ was replaced by a new assumption that (h) an activity factor, Eq.(17), the same as Eq.(16) could represent distribution of catalyst activity through the catalyst bed.

$$
k_{i}=k_{0 i} \phi_{i}\left(n_{c}\right)
$$

and

$$
\phi_{i}\left(n_{c}\right)=1-\alpha_{i} n_{c}
$$

Using the coke content a new objective function was defined by Eq.(18)

$$
\phi_{2}=\sum_{i} \sum_{j} \sum_{k}\left\{\omega_{i}\left(\hat{C}_{i j k}-C_{i j k}\right)^{2}+\omega_{n_{c}}\left(\hat{n}_{c j k}-n_{c j k}\right)^{2}\right\}
$$

where $\hat{n}_{c j k}$ and $n_{c j k}$ are the experimental and calculated values of coke content, respectively, and $\omega_{n_{c}}$ is a weighting factor for coke content. The $\phi_{i}\left(n_{c}\right)$ was substituted into Eqs.(7)-(10), and a set of Eqs. (7)-(10)

\section{Table 2 Rate constants evaluated by simulation}

$$
\begin{aligned}
& k_{1}=k_{01} \phi_{1}=\exp (10.0-17,300 / R T) \phi_{1} \\
& k_{2}=k_{02} \phi_{2}=\exp (19.4-35,200 / R T) \phi_{2} \\
& k_{3}=k_{03} \phi_{3}=\exp (9.2-16,800 / R T) \phi_{3} \\
& k_{4}=k_{04} \phi_{4}=\exp (-13.8+12,600 / R T) \phi_{4} \\
& k_{5}=k_{05} \phi_{5}=\exp (6.0-10,600 / R T) \phi_{5} \\
& \phi_{i}=1-\alpha_{i} \mathrm{n}_{c} \\
& \alpha_{1}=\exp (-14.3+15,200 / R T) \\
& \alpha_{2}=\exp (-7.9+4,700 / R T) \\
& \alpha_{5}=\exp (-20.1+24,900 / R T) \\
& \alpha_{3}=\alpha_{4}=0.0 \\
& \text { where } \omega_{A}=\omega_{B}=0.01, \omega_{C}=0.1, \omega_{n c}=1 .
\end{aligned}
$$

could be integrated by a difference method, but by use of quasi-steady state assumption, Eqs.(11)-(14) were integrated by means of the Runge-Kutta-Gill method with coke accumulation. To minimize Eq.(18), $\phi_{2}$, the decay constants, $\alpha_{i}$, and initial rate constant, $k_{0 i}$, were determined by a hill climbing method. The values of $k_{0 i}$ were plotted against the reciprocal of absolute temperature, $1 / T$, on semilogarithmic ordinates as shown in Fig. 9. The value of the constant, $\alpha_{i}$, was similarly plotted in Fig. 9, in the same way as by Takeuchi et al. ${ }^{19)}$ and Ozawa et al. ${ }^{12)}$. The rate constants and the decay constant, $\alpha_{i}$, are summarized in Table 2. Campbell and Wojciechowski ${ }^{3}$ ) defined nonselective aging such that all rate constants were multiplied by the same activity factor, and selective aging such that each rate constant was multiplied by a different activity factor. Hano et al. . $^{9}$. showed that toluene disproportionation was selective aging. In this paper, isopentane dehydrogenation is also selective aging, as shown in Table 2.

\section{Discussion}

\section{1 Coke and activation energy}

From the chemical analysis of the coke component, $\mathrm{C}_{1.0} \mathrm{H}_{0.05}-\mathrm{C}_{1.0} \mathrm{H}_{0.15}$ was obtained. It was reported that the coke component on silica-alumina catalyst ${ }^{15)}$ was $\mathrm{C}_{1.0} \mathrm{H}_{0.5}-\mathrm{C}_{1.0} \mathrm{H}_{1.0}$, and $\mathrm{C}_{1.0} \mathrm{H}_{0.5}-\mathrm{C}_{1.0} \mathrm{H}_{1.0}$ for the cracking of methylcyclohexane on silica-alumina catalyst ${ }^{21)}$ and $\mathrm{C}_{1.0} \mathrm{H}_{0.75}$ for the dehydrogenation of $n$ butane on chromia-alumina catalyst ${ }^{13}$. The reason why the values of $\mathrm{C} / \mathrm{H}$ (carbon/hydrogen) were different among investigators might be due to the complicated mechanism of such processes polymerization and adsorption. Ishii et al..$^{10,11)}$ reported that the reaction kinetics from isopentane to isopentenes was first-order with respect to each component and that the activation energy was $21.4 \mathrm{kcal} / \mathrm{g}$-mol for isopentane with hydrogen carrier gas. The evaluated activation energy was $17.3 \mathrm{kcal} / \mathrm{g}$-mol with nitrogen carrier gas. The difference between the former and the latter might be owing to the influence of the kind of carrier gas. As to the activation energy of coke formation, it was reported that for the hydrogenation of $n$-butene ${ }^{1)}$ and isobutene ${ }^{19)}$, respectively, the activation energies had values of $-3.3 \mathrm{kcal} / \mathrm{g}-\mathrm{mol}$ and $1.5 \mathrm{kcal} / \mathrm{g}$-mol. The values of $23.1 \mathrm{kcal} / \mathrm{g}$-mol and $34.6 \mathrm{kcal} / \mathrm{g}$-mol were reported, respectively, for the dehydrogenation of $n$ - 
butane ${ }^{16)}$ and cyclohexane ${ }^{14)}$. For the cracking of methylcyclohexane ${ }^{20)}$, the activation energy of -3.36 $\mathrm{kcal} / \mathrm{g}$-mol was reported. In the present work, for the activation energy of coke formation, the value of 12.6 $\mathrm{kcal} / \mathrm{g}-\mathrm{mol}$ via isopentenes and that of $-10.6 \mathrm{kcal} / \mathrm{g}$ mol via isoprene were obtained. The differences among the values of the activation energy might come from the complexity of the coke formation mechanism for each reaction.

\section{2 Kinetic parameters and expression of ac- tivity factor}

For the expression of catalyst fouling, several types of function of coke content were presented by Anderson and Whitehouse ${ }^{2)}$. The lumped activity factor, Eq. (16-2), used in several studies because of its simple form, was shown to be useful for less coke content. Froment and Bischoff ${ }^{6)}$ discussed theoretically in simple reaction models the differences of the distribution of the reactant and the coke content using the activity factor, Eq.(29). Morioka et al. ${ }^{14)}$ derived the above activity factor by Poisson distribution of coke accumulation, and used it for cyclohexane dehydrogenation.

$$
\phi_{i}=\exp \left(-\alpha_{i} n_{c}\right)
$$

If the decay constant, $\alpha$, is small, Eq.(29) can be reduced to Eq.(16-2) or Eq.(17-2) by Taylor's expan$\operatorname{sion}^{16)}$. In dehydrogenation of isopentane, Eqs.(16-2) and (17-2) were usable to estimate the changes of concentration. In the case of both lower temperature and less coke content, it is sufficient to use Eq.(16-2) and, also, it may be permissible that the reaction orders, $(p, q)$, are $(1,1)$ according to Fig. 10. Recently, the lumped activity factors as functions of process time have been developed for the design ${ }^{3,23,24)}$ or the optimization $^{15,18)}$ of the reactor. Eq.(16-2) can be reduced to the lumped activity factor as a function of process time, but as shown in Figs. 2-4, if there are distributions of coke content in the reactor length, the activity factor, i.e. Eq.(17-2), is useful to predict distribution of catalyst activity through the reactor.

\section{Conclusion}

In isopentane dehydrogenation over chromiaalumina catalyst, the conversion of isopentane and the yields of isopentenes decreased rapidly with process time while that of isoprene did so very slowly. Coke deposition on the catalyst and catalyst fouling occurred in an integral catalytic reactor, and axial coke distribution was observed along the reactor. For isopentane dehydrogenation a kinetic model was proposed in which the main reaction was consecutive and the subreaction was parallel. To evaluate distributed kinetic parameters with catalyst fouling, an algorithm involving two calculating steps was introduced. The parameter estimation method was applicable to isopentane dehydrogenation. Activity factors evaluated were different from each other, so the fouling was selective aging. The activity factor was revealed as a linear function of coke content. Using the kinetic parameters,

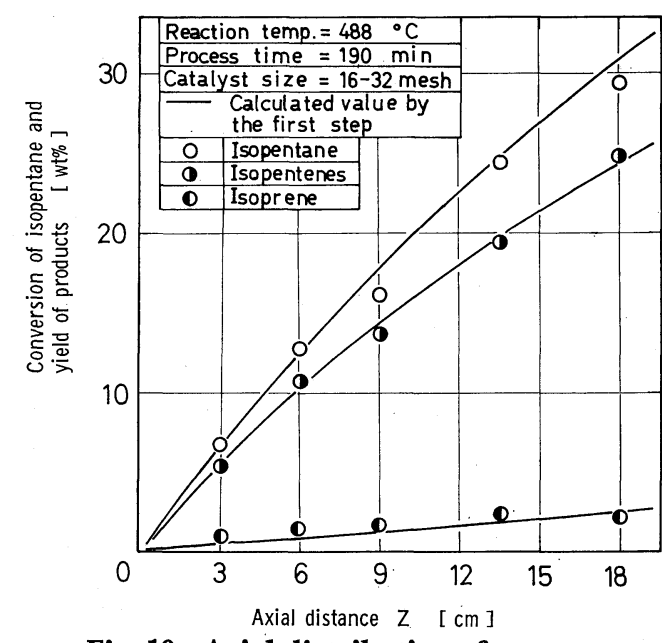

Fig. 10 Axial distribution of reactant

the changes of concentration and the distribution of coke content with process time were simulated fairly well by the kinetic model.

\section{Nomenclature}

$C_{i} \quad=$ weight fraction of the $i$-th componen

$\hat{C}_{i} \quad=$ observed weight fraction of

$\begin{array}{lll} & \text { the } i \text {-th component } & \text { [g-component } / \mathrm{g} \text {-feed] }\end{array}$

[g-component/g-feed]

$\begin{array}{lll} & \text { the } i \text {-th component } & \text { [g-component } / \mathrm{g} \text {-feed] }\end{array}$

$k_{0 j} \quad=$ rate constant for the $j$-th reaction at zero coke deposit

$[\mathrm{g} / \mathrm{min}]$

$k_{j} \quad=\begin{aligned} \text { rate constant for the } j \text {-th reaction } \\ \text { at time }\end{aligned}$

$k_{j}=\begin{aligned} & \text { rate constant for the } j \text {-th reaction } \\ & \text { at time }\end{aligned}$

$[1 / \mathrm{sec}]$

$k_{j} \quad=$ lumped rate constant for the $j$-th reaction $\quad[1 / \mathrm{sec}]$

$n_{c} \quad=$ coke content on catalyst [mg-coke/g-cat]

$\bar{n}_{c} \quad=$ average coke content on catalyst $\quad$ [mg-coke/g-cat $]$

$n_{c m} \quad=$ coke content on the $m$-th point of catalyst

- [mg-coke/g-cat] section of catalyst bed [mg-coke/g-cat]

$=$ reaction rate with respect to the $i$-th component [g-component/g-feed-sec] $=$ rate of coke formation $\quad[\mathrm{mg}-$ coke/g-cat $\cdot \mathrm{min}]$

$\begin{array}{ll}r_{n_{c}} & =\text { observed rate of coke formation } \\ \hat{r}_{n_{c}} & =\text { axial distance of the catalyst packed }\end{array}$

$\begin{array}{ll}r_{n_{c}} & =\text { observed rate of coke formation } \\ \hat{r}_{n_{c}} & =\text { axial distance of the catalyst packed }\end{array}$

$\begin{aligned} & z \quad= \text { axial distance of the catalyst packed } \\ & \text { bed from the inlet } \\ & {[\mathrm{cm}] }\end{aligned}$

$[\mathrm{mg}$-coke/g-cat $\cdot \mathrm{min}]$

$U_{v} \quad=$ vapor velocity of reactant fluid $\quad[\mathrm{cm} / \mathrm{see}]$

weat $=$ weight of catalyst

$\alpha_{i} \quad=$ decay constant in activity factor $\quad$ [g-cat $/ \mathrm{mg}$-coke]

$\bar{\alpha}_{i} \quad=$ lumped decay constant in activity factor

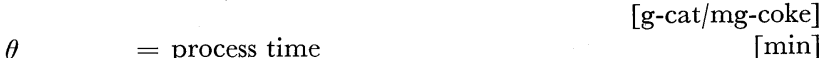

$\nu \quad=$ conversion factor

[mg-coke'g-feed $\cdot \mathrm{sec} / \mathrm{g}$-cat $\cdot \mathrm{g}$-component $\cdot \mathrm{min}]$

$\tau \quad=$ contact time $\left(=z / U_{v}\right) \quad[\mathrm{sec}]$

$\phi_{i} \quad=$ activity factor for the $i$-th reaction $\quad[-]$

$\phi \quad=$ estimation function $\quad[-]$

$\omega_{i} \quad=$ weighting factor for each component [-]

$<$ Subscripts $>$

$A \quad=$ isopentane

$B \quad=$ isopentenes

C = isoprene

$n_{c} \quad=$ coke

$m \quad=$ number of intervals of division

\section{Literature Cited}

1) Amamiya, T.: J. Research Inst. Catalysis (Hokkaido Univ.), 9, 1 (1961)

2) Anderson, R. B. and A. M. Whitehouse: Ind. Eng. Chem., 53, 
1101 (1961)

3) Campbell, D. R. and B. W. Wojciechowski: Can. J. Chem. Eng., 48, 224 (1970)

4) DiGiacorm, A. A., J. B. Maerker and J. W. Schall: Chem. Eng. Progr., 57, (5), 35 (1961)

5) Eberly, P. E., C. N. Kimberlin, W. H. Miller and H. V. Drushel: Ind. Eng. Chem. Process Design and Develop., 5, 193 (1966)

6) Froment, G. F. and K. B. Bischoff: Chem. Eng. Sci., 17, 105 (1962)

7) Gavalas, G. R., G. C. Hsu and J. H. Seinfeld: Chem. Eng. Sci., 27, 329 (1972)

8) Idem: Chem. Eng. Journal, 4, 77 (1972)

9) Hano, T. and F. Nakashio: Kagaku Kōgaku, 36, 1230 (1972)

10) Ishii, N. and K. Segawa: Preprint of the 13th meeting of the Sekiyu Gakkai, 104 (1970)

11) Idem: Sekiyu Gakkaishi, 16, 44 (1973)

12) Mavity, J. M., E. E. Zetterholm: Am. Inst. Chem. Engs., 41, 473 (1945)
13) Massoth, R. E.: Ind. Eng. Chem. Process Design and Develop., 6, (2), 200 (1967)

14) Morioka, Y., Z. Kobayashi and I. Higuchi: Nippon Kagaku Zasshi, 92, (5), 393 (1971)

15) Ogunye, A. F. and W. H. Ray: AIChE J., 17, 43 (1971)

16) Otake, T., E. Kunugita and K. Suga: Kogyo Kagaku Zasshi, 68, 58 (1965)

17) Ozawa, Y. and K. B. Bischoff: Ind. Eng. Chem. Process Design and Develop., 7, (1), 67 (1968)

18) Szépe, S. and O. Levenspiel: Chem. Eng. Sci., 23, 881 (1968)

19) Takeuchi et al.: Kagaku Kögaku, 30, 531 (1966)

20) Tone, S., H. Seko and T. Otake: Bull. Japan, Petrol. Inst., 13, (1), 39 (1971)

21) Tone, S., S. Miura and T. Otake: Bull. Japan Petrol. Inst., 14, (1), 76 (1972)

22) Voorhies, A. and P. A. Bryant: AIChE J., 14, 852 (1968)

23) Weekman, V. W.: Ind. Eng. Chem., Process Design and Develop., 7, 90 (1968)

24) Idem: ibid., 8, 385 (1969)

\title{
EVALUATION OF MASS TRANSFER EFFECTS ON CONSECUTIVE CATALYTIC REACTION USING AN INTERNAL-RECYCLE CATALYTIC REACTOR*
}

\author{
Kenji HASHIMOTO, MasaAki TERAMOTO**, Kazuhisa \\ MIYAMOTO***, Toshio TADA**** and Shinji NAGATA \\ Department of Chemical Engineering, Kyoto University, Kyoto
}

\begin{abstract}
An internal-recycle catalytic reactor is described which can be operated under perfectly mixed conditions. The reactor is suitable for evaluating intraparticle mass transfer effects on reaction rate and yield in the consecutive hydrogenation of mesityl oxide over a copper-chromium oxide catalyst. The reactor has the advantages that accurate reaction rates are directly obtained, and that mathematical formulation is simpler than with an integral reactor. Effective diffusivities are determined from conversion data and compared with those calculated by a parallel-pore model and a random-pore model. The effective diffusivities predicted by both models closely agree with each other, and these values are close to those experimentally determined. The tortuosity factors determined from the parallel-pore model range from 1.4 to 3.4 . These values fall within the range of previously published values. The calculated conversion and yield show relatively good agreement with the experimental results.
\end{abstract}

\section{Introduction}

The overall reaction rate and the selectivity in a catalytic reaction within a porous solid are markedly influenced by the intraparticle mass and heat transfer, and a large number of studies have been published on this problem ${ }^{17)}$. Many of these, however, were concerned with rather simplified reaction kinetics. Recently much attention has been paid to the effect of intraparticle diffusion on catalytic reactions in which the

* Received on July 25, 1973

A part of this paper was presented at the 1st Pacific Chem. Eng. Congress held in Kyoto, Japan, Oct. 1972.

** Faculty of Industrial Arts, Kyoto Institute of Technology

*** Department of Pharmaceutical Engineering Chemistry, Osaka University

**** Mitsubishi Rayon Co., Ltd.

于606 京都市左京区吉田本町

京都大学工学部化学工学科 橋本健治 kinetics is represented by a rate equation of the Langmuir-Hinshelwood type (L-H type $)^{6,15,16)}$. However, very few papers ${ }^{10,11)}$ dealt with the selectivity problems of multiple-reaction systems with the L-H type rate expression.

Integral tubular reactors are often employed for kinetic studies. However, even if isothermal conditions prevail in an integral reactor, the concentration distributions along an axial direction as well as within the catalyst pellet have to be considered. This fact leads to a complicated mathematical formulation. On the other hand, by the use of a catalytic reactor under perfectly mixed conditions the amount of computation is greatly reduced, because the concentration in the bulk fluid phase is uniform throughout the reactor.

Furthermore, this type of reactor has the advantages that point reaction rates of a multiple-reaction system are directly evaluated from large differences in concen- 